\title{
HIV treatment in Guinea-Bissau: room for improvement and time for new treatment options
}

\author{
S. Jespersen ${ }^{1,2^{*}}$, F. Månsson ${ }^{3}$, J. Lindman ${ }^{4}$, C. Wejse ${ }^{1,2,5}$, C. Medina ${ }^{6}$, Z. J. da Silva ${ }^{6,7}$, DdS Te ${ }^{6}$, P. Medstrand ${ }^{3}$, \\ J. Esbjörnsson ${ }^{3,8}$ and B. L. Hønge $e^{1,2}$
}

\begin{abstract}
Despite advances in the treatment quality of HIV throughout the world, several countries are still facing numerous obstacles in delivering HIV treatment at a sufficiently high quality, putting patients'lives in jeopardy. The aim of this status article is to give an overview of HIV treatment outcomes in the West African country, Guinea-Bissau, and to assess how newer treatment strategies such as long-acting injectable drugs or an HIV cure may limit or stop the HIV epidemic in this politically unstable and low-resource setting. Several HIV cohorts in Guinea-Bissau have been established and are used as platforms for epidemiological, virological, immunological and clinical studies often with a special focus on HIV-2, which is prevalent in the country. The Bandim Health Project, a demographic surveillance site, has performed epidemiological HIV surveys since 1987 among an urban population in the capital Bissau. The Police cohort, an occupational cohort of police officers, has enabled analyses of persons seroconverting with estimated times of seroconversion among HIV-1 and HIV-2-infected individuals, allowing incidence measurements while the Bissau HIV Cohort and a newer Nationwide HIV Cohort have provided clinical data on large numbers of HIV-infected patients. The HIV cohorts in Guinea-Bissau are unique platforms for research and represent real life in many African countries. Poor adherence, lack of HIV viral load measurements, inadequate laboratory facilities, high rates of loss to follow-up, mortality, treatment failure and resistance development, are just some of the challenges faced putting the goal of "90-90-90" for Guinea-Bissau well out of reach by 2020. Maintaining undetectable viral loads on treatment as a prerequisite of a cure strategy seems not possible at the moment. Thinking beyond one-pill-once-a-day, long-acting antiretroviral treatment options such as injectable drugs or implants may be a better treatment option in settings like Guinea-Bissau and may even pave the way for an HIV cure. If the delivery of antiretroviral treatment in sub-Saharan Africa in a sustainable way for the future should be improved by focusing on existing treatment options or through focusing on new treatment options remains to be determined.
\end{abstract}

Keywords: HIV-1, HIV-2, Dual infection, Antiretroviral treatment, Guinea-Bissau, West Africa

\section{Introduction}

Despite advances in the treatment quality of HIV throughout the world, several countries are still facing numerous obstacles in delivering HIV treatment at a

*Correspondence: sanne.jespersen@clin.au.dk

${ }^{1}$ Department of Infectious Diseases, Aarhus University Hospital, Palle Juul-Jensens Boulevard 99, 8200 Aarhus N, Denmark

Full list of author information is available at the end of the article sufficiently high quality, putting patients' lives in jeopardy $[1,2]$. In many West African countries, the level of pre-treatment drug resistance exceeds $10 \%$, indicating that programs need to take actions to prevent further development of drug resistance, which may include the transition from non-nucleoside reverse transcriptase inhibitors (NNRTIs) to more robust drug classes [3, 4]. This is especially true for Guinea-Bissau. Poor adherence, high rates of loss to follow-up, lack of HIV viral 
load (VL) measurements, lack of reliable diagnostic tests for opportunistic infections, inadequate laboratory facilities (including transportation of reagents and service of equipment) as well as low numbers of sufficiently trained staff are just some of the challenges faced [5-10]. The aim of this status article is to give an overview of HIV treatment outcomes in Guinea-Bissau. We also aim to assess how newer treatment strategies such as longacting injectable drugs or an HIV cure may limit or stop the HIV epidemic in this politically unstable and lowresource setting.

\section{HIV epidemiology in Guinea-Bissau}

According to the joint United Nations programme on HIV/AIDS (UNAIDS), the HIV prevalence among adults (15-49 years) in Guinea-Bissau was 3.4\% (95\% CI 2.6-3.8) in 2017 but disparities exist within the country [11]. HIV-2 was discovered two years after HIV-1 [12] and has mainly been restricted to West Africa, where an estimated 1-2 million people are infected with the virus [13]. To evaluate the trends in HIV prevalence and incidence in Guinea-Bissau, the Bandim Health Project (BHP), a demographic surveillance site, has performed epidemiological HIV surveys since 1987 among an urban population in the capital Bissau. In the first BHP survey from 1987, HIV-1 was nonexistent [14]. Two years later the first HIV-1/HIV-2 dual infection was identified in a community cohort study [15]. The prevalence of HIV-1 increased from zero to 4.6\% between 1987 and 2006, where it now seems to have stabilized (also the 2016 survey indicated a prevalence of $4.0 \%$, Fig. 1 , adapted from reference 18) [16-18]. In contrast to HIV-1, HIV-2 has been steadily decreasing in prevalence from $8.9 \%$ in 1987 [14] to $2.8 \%$ in 2016 [16-18]. The underlying reasons for this decline in HIV-2 prevalence is not known. However, it is possible that the high HIV-2 prevalence seen during

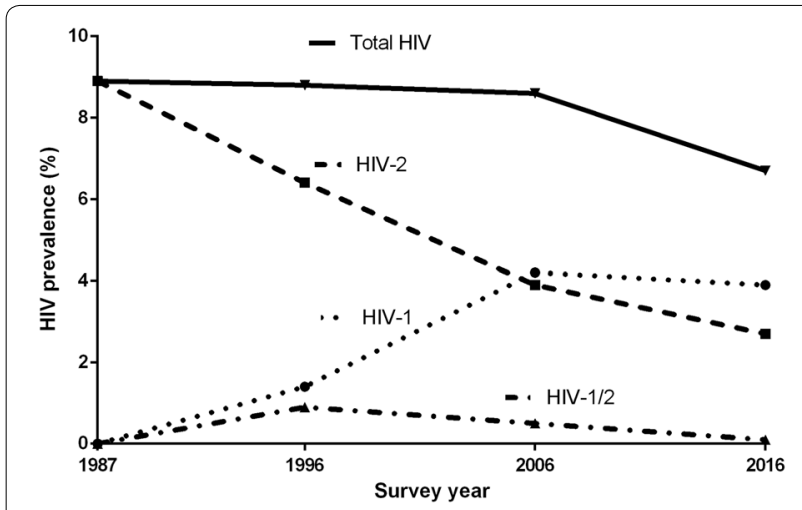

Fig. 1 HIV prevalence in four cross-sectional surveys from Bissau, Guinea-Bissau (Adapted from reference [18]) the 1980s was a result of high levels of commercial sex work and blood transfusions during the war of independence from 1963 to 1974 and that the decline in prevalence reflects the low rates of sexual and vertical transmission that is associated with HIV-2 infection [19-21].

\section{The police cohort}

In 1990 an occupational cohort of police officers was initiated in Bissau, supported by the bilateral aid and research program of Swedish SIDA/Sarec. The cohort has been open and prospective, with continuing new recruitment until the civil war broke out in June 1998. Regular follow-up visits were resumed in the year 2000 and new recruitment to the cohort was re-initiated in the year 2003. Until 2011, regular follow-ups were performed, followed by targeted follow-ups since then. Visits were made to police stations in the capital as well as in the interior regions of the country. Follow-up visits were scheduled every 12-18 months, with continuous collection of demographic information and clinical examinations of symptoms related to HIV and sexually transmitted infections. Serological sampling of HIV, HTLV and syphilis were performed. For HIV-infected individuals CD4+ $\mathrm{T}$ cell counts have been performed since 1993. By 2011, 4820 police officers had been enrolled, of whom 4817 had a recorded HIV test result. Antiretroviral drugs were provided under the umbrella of the national antiretroviral treatment (ART) programme, initiated in 2005, commencing in the Police cohort in January 2006. The continuous follow-up has enabled analyses of persons seroconverting with estimated times of seroconversion among HIV-1 and HIV-2-infected individuals, allowing incidence measurements [22], as well as unique observations on the natural course of HIV-1 and HIV-2 before treatment became available [23], as well as observations on the interaction between HIV-1 and HIV-2 [24-26]. Collected blood samples has enabled in-depth studies of virological and immunological correlates of HIV-1 and HIV-2-related disease [3, 27-38].

\section{The Bissau HIV cohort}

In 2007, an HIV cohort was set up in Bissau by the BHP and Aarhus University Hospital in Denmark in collaboration with nurses and physicians from Hospital National Simão Mendes (HNSM). HNSM is the main hospital in Guinea-Bissau and is located in Bissau [2]. All HIVinfected patients presenting at the HIV clinic are invited to be enrolled in the cohort. Demographic and clinical data are collected at baseline and at all follow-up visits, together with CD4 $+\mathrm{T}$ cell count and routine biochemistry analyses. Due to frequent power cuts in Bissau, plasma and cells are stored in a biobank in Denmark. The cohort currently has recruited $>6500$ patients $(64 \%$ 
HIV-1, 11\% HIV-2, 8\% HIV-1/2 and 17\% with unknown HIV-type) and is unique because it comprises the world's largest single-center cohort of HIV-2 and HIV-1/2 dually infected patients. The median age at time of inclusion is 36 years (interquartile range 29-45) with the majority of patients being female (63\%). Other infections are coprevalent in Guinea-Bissau, including tuberculosis [39], HTLV-1 [40-42] and hepatitis [43, 44], creating a unique opportunity to study different co-infections' effect on disease progression, immune response and response to treatment. The cohort is used as a platform for epidemiological, virological, immunological and clinical studies. The international research collaborations between highand low-resource settings have helped to identify problems related to delivery of ART [1].

\section{A nationwide HIV cohort in Guinea-Bissau}

As the HIV clinic at HNSM is a referral clinic, and the largest HIV clinic in Guinea-Bissau in terms of number of patients on follow-up, data from this clinic may not always reflect estimates from other HIV clinics in the country. Clinics vary in terms of size, human resources, geography of the area, management, organization and structure. Thus, to address challenges such as mortality and loss to follow-up on a nationwide scale in GuineaBissau, a nationwide HIV Cohort was established in 2017 and has now included more than 30,000 patients from nine HIV clinics in the country covering around $90 \%$ of all HIV-infected patients enrolled in care in the country. Demographic and clinical data are collected at each patient visit using the same database as for the Bissau HIV Cohort. Comparing patients' outcome between different clinics, may shed light on the best way of organizing clinics, and ultimately improve the quality of care for HIV-infected individuals in Guinea-Bissau. Furthermore, having a nationwide database can make it possible to see if patients who are thought to be lost to follow-up, in reality have transferred to a different clinic.

\section{HIV treatment and problems related to ART delivery}

In 2005, the Ministry of Health in Guinea-Bissau implemented a national HIV program. During 2007, the program experienced an increase in the number of patients initiating ART, which is free of charge. Unfortunately, the delivery of ART is still facing a multitude of challenges (Table 1). For years, Guinea-Bissau has struggled with political instability, leaving the health sector in a poor state. Frequent HIV clinic relocations and inadequate drug supply leading to treatment interruptions has underscored the need to improve stock management and increase investment in health-care infrastructure and capacity as well as giving the disease a higher priority among policymakers [1]. The HIV-2 prevalence has been declining in Bissau long before ART was introduced and from population-based surveys it seems that ART has had little effect on the pace of the declining HIV-2 prevalence $[18,22,45-47]$.

\section{Loss to follow-up and adherence}

HIV-infected patients in Guinea-Bissau are facing major adherence difficulties and high rates of loss-to-followup. A retrospective study among patients in the Bissau HIV Cohort found that 7 years after ART initiation, $56 \%$ were lost to the programme, of which $75.9 \%$ were lost to follow-up (LTFU), $17.8 \%$ died and $6.3 \%$ transferred [8]. Main reasons reported for loss to follow-up in Guinea-Bissau are moving (29.1\%), travelling (17.5\%) and transferring to other clinics (11.7\%), suggesting that the majority of the patients LTFU have extended periods of time without, or is no longer receiving ART [48]. A cross-sectional study found that of patients on ART only $14 \%$ reported not having missed any dose of ART within the past four days, and conversely only $4 \%$ had an adherence of $90 \%$ during the last month [49]. This indicate that $86-96 \%$ were susceptible to viral failure and disease progression. Moreover, people receiving ART, but who did not attend the clinic as scheduled had a higher risk of non-adherence. Furthermore, non-adherent patients had a lower level of HIV related knowledge suggesting that patients with adherence problems lack the required knowledge to follow the ART regimen, and are thereby in risk of developing viral failure $[49,50]$.

\section{Monitoring of treatment and failure}

Clinical assessment and laboratory tests play a key role in monitoring the response to treatment and the possible toxicity of ART. According to the WHO Guidelines, VL is recommended as the preferred monitoring approach to diagnose treatment failure. However, CD4 $+\mathrm{T}$ cell count and clinical monitoring should be used to diagnose treatment failure if VL is not widely available as is the case in Guinea-Bissau [51]. Previous studies from Guinea-Bissau have also shown that both $\mathrm{CD} 4+\mathrm{T}$ cell counts (particularly CD4 percentages) and VL are strongly correlated with disease progression in both HIV-1 and HIV-2 infection [10, 24, 33, 52]. Immunological treatment failure is common among patients in the Bissau HIV Cohort. In a study from 2015, immunological treatment failure was detected in $25 \%$, while treatment failure could not be assessed in $37 \%$ due to missing CD4+ T cell counts [5], underscoring the problems with lack of laboratory facilities and tests. Recently, a commercial real-time PCRbased HIV-2 VL platform was released (Generic HIV-2, Biocentric, France). However, with the large number of challenges that Guinea-Bissau and many other west African countries face with such assays (e.g. transportation of 
reagents, keeping the cold chain, stable long-term storage of reagents), developments of other platforms are needed (e.g. an HIV-2 GenXpert platform [Cepheid, USA]) including implementation of point-of-care VL testing [53]. In addition, identification of new biomarkers could provide future opportunities for monitoring of HIV disease progression and ART outcome in HIV infection. The scale-up of effective VL testing is an urgent public health priority and Guinea-Bissau is still lacking behind many other African countries [54].

\section{Resistance}

Poor adherence in a setting where NNRTIs are among the most commonly used ARTs will eventually lead to development of resistance. High rates of NNRTI resistance among HIV-1 infected patients have been seen in studies from the Bissau HIV Cohort and may compromise the future use of this drug class. Genotypes from time of virological failure among patients in the PIONA trial revealed that $73 \%$ of patients with virological failure receiving NNRTIs had any nucleoside reverse transcriptase inhibitor (NRTI) or NNRTI mutation [7]. In an observational study of 36 patients with virological failure, resistance testing was performed in 15 patients whereof nine patients $(9 / 15 ; 60 \%)$ had resistance mutations. The most common mutation was $\mathrm{K} 103 \mathrm{~N}$, which confers highlevel resistance to NNRTIs [6]. Moreover, a recent study with 48 participants demonstrated a $10.4 \%$ prevalence of pre-treatment drug resistance to NNRTIs in HIV-1-infected pregnant women in the capital Bissau [4].

HIV-2 is naturally resistant to the NNRTIs [55] and enfuvirtide [56] while integrase inhibitors including dolutegravir are effective against HIV-2 isolates [5760]. Reduced susceptibility to some protease inhibitors (PIs) has been observed, ritonavir-boosted lopinavir and darunavir being the most active drugs $[61,62]$. The

\section{Table 1 Challenges related to HIV treatment in Guinea-} Bissau

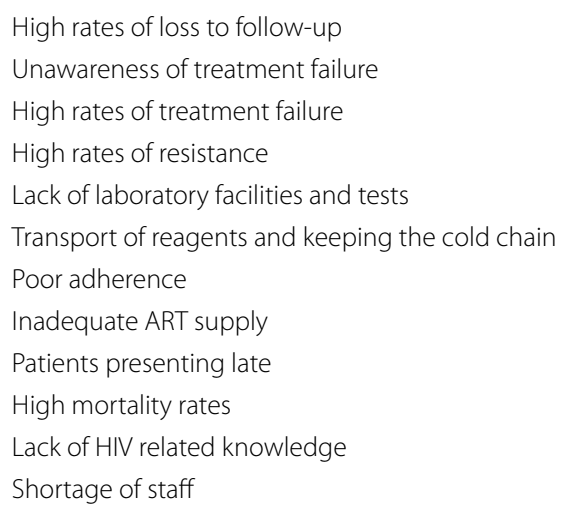

World Health Organization recommends dolutegravir containing regimens as the preferred first-line regimen for people living with HIV regardless of HIV type [63]. Resistance-associated mutations against NRTIs, PIs and integrase inhibitors may be selected in HIV-2-infected patients while on therapy [64] but data on HIV-2 resistance in West African patients are scarce [65-68]. However, transmitted drug resistance seems to be rare among HIV-2 infected patients [69]. Algorithms that are used to predict drug resistance in HIV-1 may not be applicable to HIV-2, because the pathways and mutational patterns that lead to resistance differ between the HIV types [70]. In cases of virological failure, HIV-2 resistance is common and the limited HIV-2 therapeutic arsenal and cross-resistance reduces treatment options [67].

\section{Mortality}

In recent time, prognosis of HIV-infected patients has improved to the point where it is possible for a patient to live close to a normal life, if on treatment [71-73]. Several studies on life expectancy in HIV-infected individuals have been performed in Africa, showing life expectancy among patients on ART to be close to those of the background population [74-77]. However, many of these studies are from well-established and well-functioning clinics, and the efficiency of HIV treatment may be lower in other parts of Africa. The success of ART depends on the disease progression at HIV diagnosis, and low CD4+ $\mathrm{T}$ cell count at HIV diagnosis has been associated with higher mortality [78]. Almost half of the patients in the Bissau HIV Cohort are presenting with CD4+ $\mathrm{T}$ cell counts below 200 cells $/ \mu \mathrm{L}$ and additional one quarter with a CD4+ T cell counts below 350 cells $/ \mu \mathrm{L}$ [79]. The overall mortality rate was 7.7 per 100 person-years with a higher mortality among patients presenting late and a higher mortality among men $[79,80]$. Even though HIV-2 is considered more benign and has fewer pathogenic consequences than HIV-1 for most infected individuals, studies from the Police cohort in Bissau have shown that both HIV-1-infected and HIV-2-infected individuals have a high probability of developing and dying from AIDS without ART [23]. This could partly be explained by the fact that people living with HIV-2 initiate ART later than patients with HIV-1, resulting in higher disease progression and mortality rate [81].

\section{0-90-90 goals}

To effectively fight the HIV epidemic, UNAIDS have set forth a series of treatment goals. By 2020, $90 \%$ of all HIV-infected individuals should be diagnosed. Of these, 90\% should be enrolled in ART and $90 \%$ of these should be virally suppressed [82]. In low income countries, it is often impossible to correctly asses each branch of the 
treatment cascade, due to a lack of data, but based on the results from the newest BHP HIV survey [18], and routine analysis from the nationwide HIV Cohort in GuineaBissau, preliminary results show that only around $14 \%$ of infected individuals are aware of their disease. Of these, only $20 \%$ are on treatment, and among patients on treatment in the PIONA trial only $33 \%$ were virologically suppressed after one year of ART [7]. These rates are lower than those reported in a review of 89 studies from sub-Saharan Africa in which $78 \%$ viral suppression was achieved after 6 months of ART [83]. Maintaining undetectable VL on treatment is at the moment not possible in Guinea-Bissau. Overall, this puts the goal of "90-9090" for Guinea-Bissau well out of reach by 2020 .

\section{Perspectives regarding long-acting ARTs and HIV cure}

In many parts of the World, the extensive use of ART for patients infected with HIV has decreased mortality, improved lives and decreased transmission. The $\mathrm{U}=\mathrm{U}$ campaign [84] underscoring that patients with undetectable VL in the blood cannot transmit the virus as well as the few side effects from never ART regimens have decreased the need for an HIV cure in countries with well-functioning HIV care and treatment programs. However, in Guinea-Bissau, traditional ART delivery is still not successful due to various obstacles. Maintaining undetectable $\mathrm{VL}$ on treatment as a prerequisite of a cure strategy seems not possible at the moment. Thinking beyond one-pill-once-a-day, long-acting ARTs such as injectable drugs or implants may be a better treatment option in settings like Guinea-Bissau and may even pave the way for an HIV cure. Since HIV-2 seems to be susceptible to integrase inhibitors, long-acting Cabotegravir may even be a valid option in all patients irrespective of HIV type, making the problem with unreliable HIV discriminatory rapid tests less important $[9,85,86]$. These methods will also require patients to show up for injections at regular intervals but long-acting ARTs provide invisibility to oneself, one's partner and household members, and has been preferred in some African studies [87]. Furthermore, long-acting depot progesterone as contraception has been widely used in Africa, making regular injections an acceptable treatment tool.

\section{Conclusions}

Guinea-Bissau still faces numerous challenges in delivering ART at a sufficiently high quality level, and as a result patients' lives are in jeopardy. The three main HIV cohorts in Guinea-Bissau are unique platforms for research and represent real life in many African countries. Despite difficult working conditions, we have maintained inclusion and follow-up in these cohorts for many years and kept a large number of patients on treatment.
The constraints we face are probably also experienced by the many ART facilities in Africa that do not report their data and thereby increasing the risk of publication bias. This may impair further sustainability of ART programs if decisions are based on data not being representative of the general situation. If the delivery of ART in sub-Saharan Africa in a sustainable way for the future should be improved by focusing on existing treatment options or through focusing on new treatment options remains to be determined.

\section{Abbreviations}

ART: antiretroviral treatment; BHP: Bandim Health Project; HNSM: Hospital National Simão Mendes; LTFU: lost to follow-up; NRTI: nucleoside reverse transcriptase inhibitor; NNRTIs: non-nucleoside reverse transcriptase inhibitors; PIs: protease inhibitors; VL: viral load.

\section{Acknowledgements and Funding}

The authors are grateful to all cohort participants, and the healthcare personnel at the HIV clinics in Guinea-Bissau for providing medical care and data acquisition for the HIV-infected patients of the cohorts. The Bissau HIV cohort study group comprises: Amabelia Rodrigues, David da Silva, Zacarias José da Silva, Candida Medina, Ines Oliviera-Souto, Lars Østergaard, Alex Laursen, Peter Aaby, Anders Fomsgaard, Christian Erikstrup, Bo Langhoff Hønge, Christian Wejse and Sanne Jespersen (chair). Current members of the Sweden GuineaBissau Cohort Research (SWEGUB CORE) group are: Babetida N'Buna, Antonio J Biague, Ansu Biai, Cidia Camara, Joakim Esbjörnsson, Marianne Jansson, Sara Karlson, Jacob Lindman, Patrik Medstrand, Fredrik Månsson, Hans Norrgren, Angelica A Palm, Gülsen Özkaya Sahin, Zacarias J da Silva, and Sten Wilhelmson. We also thank all the personnel at the Health Station of the 2a esquadra, Bissau, and at the National Public Health Laboratory in Bissau. The HIV cohorts in Guinea-Bissau have received funding from private and public Danish funds, Global Fund to Fight AIDS, TB and Malaria, Unicef, International epidemiology Databases to Evaluate AIDS (leDEA), West African Platform for HIV Intervention Research (WAPHIR), Bandim Health Project, the Department for Research Cooperation (SAREC) at the Swedish International Development Agency (SIDA), the Swedish Research Council (No. 350-2012-6628 and 2016-01417 for JE; No. 2016-02285 for MJ; No. 321-2012-3274 for PM), Swedish Society of Medical Research, Medical Faculty at Lund University (ALF), and Region Skåne FoU.

\section{Authors' contributions}

All authors contributed in writing the manuscript. All authors read and approved the final manuscript.

Availability of data and materials Not applicable.

Ethics approval and consent to participate

Not applicable.

Consent for publication

Not applicable.

\section{Competing interests}

The authors declare that they have no competing interests.

\section{Author details}

${ }^{1}$ Department of Infectious Diseases, Aarhus University Hospital, Palle Juul-Jensens Boulevard 99, 8200 Aarhus N, Denmark. ${ }^{2}$ Bandim Health Project, Indepth Network, Apartado 861, 1004 Bissau Codex, Guinea-Bissau. ${ }^{3}$ Department of Translational Medicine, Lund University, J Waldenströms gata 35, 205 02 Malmö, Sweden. ${ }^{4}$ Department of Clinical Sciences Lund, Division of Infection Medicine, Lund University, BMC F12, 22184 Lund, Sweden. ${ }^{5}$ GloHAU, Center for Global Health, Department of Public Health, Aarhus University, Bartholins Allé 2, 8000 Aarhus, Denmark. ${ }^{6}$ National HIV Programme, Ministry 
of Health, Bissau, Apartado 861, 1004 Bissau Codex, Guinea-Bissau. ${ }^{7}$ National Public Health Laboratory, CP 1013 Bissau, Guinea-Bissau. ${ }^{8}$ Nuffield Department Medicine, University of Oxford, Old Road Campus, Headington, Oxford OX3 7BN, UK.

Received: 16 June 2019 Accepted: 21 January 2020

Published online: 04 February 2020

\section{References}

1. Jespersen S, Hønge BL, Oliveira I, Medina C, da Silva Te D, Correia FG, et al. Challenges facing HIV treatment in Guinea-Bissau: the benefits of international research collaborations. Bull World Health Organ. 2014;92(12):909-14.

2. Jespersen S, Honge BL, Oliveira I, Medina C, da Silva Te D, Correira FG, et al. Cohort profile: the Bissau HIV cohort-a cohort of HIV-1, HIV-2 and co-infected patients. Int J Epidemiol. 2015;44(3):756-63.

3. Ngo-Giang-Huong N, Huynh THK, Dagnra AY, Toni TD, Maiga Al, Kania D, et al. Prevalence of pretreatment HIV drug resistance in West African and Southeast Asian countries. J Antimicrob Chemother. 2019;74(2):462-7.

4. Wilhelmson S, Mansson F, Lopatko Lindman J, Biai A, Esbjornsson J, Norrgren $\mathrm{H}$, et al. Prevalence of HIV-1 pretreatment drug resistance among treatment naive pregnant women in Bissau, Guinea Bissau. PLoS ONE. 2018;13(10):e0206406.

5. Jespersen S, Honge BL, Medina C, da Silva Te D, Correira FG, Laursen $A L$, et al. Lack of awareness of treatment failure among HIV-1-infected patients in Guinea-Bissau — a retrospective cohort study. J Int AIDS Soc. 2015;18:20243

6. Jespersen S, Tolstrup M, Honge BL, Medina C, Te Dda S, Ellermann-Eriksen $\mathrm{S}$, et al. High level of HIV-1 drug resistance among patients with HIV-1 and HIV-1/2 dual infections in Guinea-Bissau. Virol J. 2015;12:41.

7. Jespersen S, Hønge BL, Krarup H, Medstrand P, Sørensen A, Medina C, da Silva Té D, Correira FG, Erikstrup C, Østergaard L, Wejse C. Protease inhibitors or NNRTIs as first-line HIV-1 treatment in West Africa (PIONA): a randomized controlled trial. J Acquir Immune Defic Syndr. 2018;79(3):386-93.

8. Honge BL, Jespersen S, Nordentoft PB, Medina C, da Silva D, da Silva $\mathrm{ZJ}$, et al. Loss to follow-up occurs at all stages in the diagnostic and follow-up period among HIV-infected patients in Guinea-Bissau: a 7-year retrospective cohort study. BMJ Open. 2013;3(10):e003499.

9. Honge BL, Bjarnason Obinah MP, Jespersen S, Medina C, Te Dda S, da Silva ZJ, et al. Performance of 3 rapid tests for discrimination between HIVand HIV-2 in Guinea-Bissau, West Africa. J Acquir Immune Defic Syndr. 2014;65(1):87-90.

10. Esbjornsson J, Mansson F, Lindman J, Rowland-Jones SL, Jansson M, Medstrand $\mathrm{P}$, et al. New insights are game-changers in HIV-2 disease management-authors' reply. Lancet HIV. 2019;6(4):e214-5.

11. UNAIDS. http://www.unaids.org/en/regionscountries/countries/guine a-bissau.

12. Clavel F, Guetard D, Brun-Vezinet F, Chamaret S, Rey MA, Santos-Ferreira $\mathrm{MO}$, et al. Isolation of a new human retrovirus from West African patients with AIDS. Science. 1986;233(4761):343-6.

13. Arien KK, Abraha A, Quinones-Mateu ME, Kestens L, Vanham G, Arts EJ. The replicative fitness of primary human immunodeficiency virus type 1 (HIV-1) group M, HIV-1 group O, and HIV-2 isolates. J Virol. 2005;79(14):8979-90.

14. Poulsen AG, Kvinesdal B, Aaby P, Molbak K, Frederiksen K, Dias F, et al. Prevalence of and mortality from human immunodeficiency virus type 2 in Bissau, West Africa. Lancet. 1989;1 (8642):827-31.

15. Poulsen AG, Aaby P, Gottschau A, Kvinesdal BB, Dias F, Molbak K, et al. HIV-2 infection in Bissau, West Africa, 1987-1989: incidence, prevalences, and routes of transmission. J Acquir Immune Defic Syndr. 1993;6(8):941-8

16. Larsen O, da Silva Z, Sandstrom A, Andersen PK, Andersson S, Poulsen AG, et al. Declining HIV-2 prevalence and incidence among men in a community study from Guinea-Bissau. AIDS. 1998;12(13):1707-14.

17. da Silva ZJ, Oliveira I, Andersen A, Dias F, Rodrigues A, Holmgren B, et al. Changes in prevalence and incidence of HIV-1, HIV-2 and dual infections in urban areas of Bissau, Guinea-Bissau: is HIV-2 disappearing? AIDS. 2008:22(10):1195-202.
18. Olesen JS, Jespersen S, da Silva ZJ, Rodrigues A, Erikstrup C, Aaby P, et al. HIV-2 continues to decrease, whereas HIV-1 is stabilizing in Guinea-Bissau. AIDS. 2018;32(9):1193-8.

19. Poulsen AG, Aaby P, Jensen H, Dias F. Risk factors for HIV-2 seropositivity among older people in Guinea-Bissau. A search for the early history of HIV-2 infection. Scand J Infect Dis. 2000;32(2):169-75.

20. van der Loeff MFS, Aaby P. Towards a better understanding of the epidemiology of HIV-2. AIDS. 1999;13(A):S69-84.

21. Pepin J, Plamondon M, Alves AC, Beaudet M, Labbe AC. Parenteral transmission during excision and treatment of tuberculosis and trypanosomiasis may be responsible for the HIV-2 epidemic in Guinea-Bissau. AIDS. 2006;20(9):1303-11.

22. Mansson F, Biague A, da Silva ZJ, Dias F, Nilsson LA, Andersson S, et al, Prevalence and incidence of HIV-1 and HIV-2 before, during and after a civil war in an occupational cohort in Guinea-Bissau, West Africa. AIDS. 2009;23(12):1575-82

23. Esbjornsson J, Mansson F, Kvist A, Silva ZJ, Andersson S, Fenyo EM, et al. Long-term follow-up of HIV-2-related AIDS and mortality in GuineaBissau: a prospective open cohort study. Lancet HIV. 2018. https://doi. org/10.1016/S2352-3018(18)30254-6.

24. Esbjornsson J, Mansson F, Kvist A, Isberg PE, Nowroozalizadeh S, Biague AJ, et al. Inhibition of HIV-1 disease progression by contemporaneous HIV-2 infection. N Engl J Med. 2012;367(3):224-32.

25. Esbjornsson J, Mansson F, Kvist A, Isberg PE, Nowroozalizadeh S, Biague AJ, et al. Effect of HIV-2 infection on HIV-1 disease progression and mortality. AIDS. 2014;28(4):614-5.

26. Esbjornsson J, Mansson F, Kvist A, Isberg PE, Biague AJ, da Silva ZJ, et al. Increased survival among HIV-1 and HIV-2 dual-infected individuals compared to HIV-1 single-infected individuals. Aids. 2014;28(7):949-57.

27. Palm AA, Esbjornsson J, Mansson F, Biague A, da Silva ZJ, Norrgren $H$, et al. Cocirculation of several similar but unique HIV-1 recombinant forms in Guinea-Bissau revealed by near full-length genomic sequencing. AIDS Res Hum Retroviruses. 2015;31 (9):938-45.

28. Palm AA, Esbjornsson J, Mansson F, Kvist A, Isberg PE, Biague A, et al. Faster progression to AIDS and AIDS-related death among seroincident individuals infected with recombinant HIV-1 A3/CRF02_AG compared with sub-subtype A3. J Infect Dis. 2014;209(5):721-8.

29. Ozkaya Sahin G, Holmgren B, da Silva Z, Nielsen J, Nowroozalizadeh S, Esbjornsson J, et al. Potent intratype neutralizing activity distinguishes human immunodeficiency virus type 2 (HIV-2) from HIV-1. J Virol. 2012;86(2):961-71.

30. Vinner L, Holmgren B, Jensen KJ, Esbjornsson J, Borggren M, Hentze JL, et al. Sequence analysis of HIV-1 isolates from Guinea-Bissau: selection of vaccine epitopes relevant in both West African and European countries. APMIS. 2011;119(8):487-97.

31. Esbjornsson J, Mild M, Mansson F, Norrgren H, Medstrand P. HIV-1 molecular epidemiology in Guinea-Bissau, West Africa: origin, demography and migrations. PLoS ONE. 2011;6(2):e17025.

32. Esbjornsson J, Mansson F, Martinez-Arias W, Vincic E, Biague AJ, da Silva $\mathrm{ZJ}$, et al. Frequent CXCR4 tropism of HIV-1 subtype A and CRF02_AG during late-stage disease-indication of an evolving epidemic in West Africa. Retrovirology. 2010;7:23.

33. Palm AA, Lemey $P$, Jansson M, Månsson F, Kvist A, Szojka Z, et al. Low postseroconversion CD4+ T-cell level is associated with faster disease progression and higher viral evolutionary rate in HIV-2 infection. mBio. 2019;10(1):e01245-18

34. Karlsson I, Tingstedt JL, Sahin GO, Hansen M, Szojka Z, Buggert M, et al. Cross-reactive antibodies with the capacity to mediate hiv-1 envelope glycoprotein-targeted antibody-dependent cellular cytotoxicity identified in HIV-2-Infected individuals. J Infect Dis. 2019;219(11):1749-54.

35. Buggert M, Frederiksen J, Lund O, Betts MR, Biague A, Nielsen M, et al. $C D 4+T$ cells with an activated and exhausted phenotype distinguish immunodeficiency during aviremic HIV-2 infection. AIDS. 2016:30(16):2415-26.

36. Bachle SM, Malone DF, Buggert M, Karlsson AC, Isberg PE, Biague AJ, et al. Elevated levels of invariant natural killer T-cell and natural killer cell activation correlate with disease progression in HIV-1 and HIV-2 infections. AIDS. 2016;30(11):1713-22.

37. Ozkaya Sahin G, Mansson F, Palm AA, Vincic E, da Silva Z, Medstrand $P$, et al. Frequent intratype neutralization by plasma immunoglobulin 
a identified in HIV type 2 infection. AIDS Res Hum Retroviruses. 2013;29(3):470-8.

38. Nowroozalizadeh S, Mansson F, da Silva Z, Repits J, Dabo B, Pereira C, et al. Microbial translocation correlates with the severity of both HIV-1 and HIV-2 infections. J Infect Dis. 2010;201(8):1150-4.

39. Wejse C, Patsche CB, Kuhle A, Bamba FJ, Mendes MS, Lemvik G, et al. Impact of HIV-1, HIV-2, and HIV-1 + 2 dual infection on the outcome of tuberculosis. IJID. 2015;32:128-34.

40. van Tienen C, van der Loeff MF, Peterson I, Cotten M, Holmgren B, Andersson S, et al. HTLV-1 in rural Guinea-Bissau: prevalence, incidence and a continued association with HIV between 1990 and 2007. Retrovirology. 2010;7:50.

41. Norrgren $\mathrm{H}$, Andersson S, Naucler A, Dias F, Johansson I, Biberfeld G. HIV-1, HIV-2, HTLV-I/II and Treponema pallidum infections: incidence, prevalence, and HIV-2-associated mortality in an occupational cohort in Guinea-Bissau. J Acqui Immune Defic Syndr Hum Retrovirol. 1995;9(4):422-8.

42. Jensen MM, Olesen JS, Kjerulff B, Byberg S, da Silva ZJ, Rodrigues A, et al. HTLV prevalence is no longer following the decreasing HIV prevalence - 20 years of retroviral surveillance in Guinea-Bissau, West Africa. Acta Tropica. 2019;192:144-50.

43. Hønge BL, Jespersen S, Medina C, Te Dda S, da Silva ZJ, Lewin S, et al. Hepatitis $B$ and delta virus are prevalent but often subclinical coinfections among HIV infected patients in Guinea-Bissau, West Africa: a cross-sectional study. PLoS ONE. 2014;9(6):e99971.

44. Honge BL, Jespersen S, Medina C, da Silva Te D, da Silva ZJ, Lewin SR, et al. Hepatitis C prevalence among HIV-infected patients in Guinea-Bissau: a descriptive cross-sectional study. IJID. 2014;28:35-40.

45. Mansson F, Alves A, Silva ZJ, Dias F, Andersson S, Biberfeld G, et al. Trends of HIV-1 and HIV-2 prevalence among pregnant women in Guinea-Bissau, West Africa: possible effect of the civil war 1998 1999. Sex Transm Infect 2007;83(6):463-7.

46. Mansson F, Camara C, Biai A, Monteiro M, da Silva ZJ, Dias F, et al. High prevalence of HIV-1, HIV-2 and other sexually transmitted infections among women attending two sexual health clinics in Bissau, GuineaBissau. West Africa. Int J STD AIDS. 2010;21(9):631-5.

47. Biague A, Mansson F, da Silva Z, Dias F, Nantote Q, Costa J, et al. High sexual risk taking and diverging trends of HIV-1 and HIV-2 in the military of Guinea Bissau. J Infect Dev Ctries. 2010;4(5):301-8.

48. Nordentoft PB, Engell-Sorensen T, Jespersen S, Correia FG, Medina C, da Silva Te D, et al. Assessing factors for loss to follow-up of HIV infected patients in Guinea-Bissau. Infection. 2017:45(2):187-97.

49. Dyrehave C, Rasmussen DN, Hønge BL, Jespersen S, Correia FG, Medina $C$, et al. Nonadherence is associated with lack of HIV-related knowledge: a cross-sectional study among HIV-infected individuals in Guinea-Bissau. J Int Assoc Provid AIDS Care. 2016:15(4):350-8.

50. Rasmussen DN, Te DdS, Roedkjaer L, Oliveira I, Medinca C, Barfod T, et al. Barriers and facilitators to antiretroviral therapy adherence among patients with HIV in Bissau, Guinea-Bissau: a qualitative study. Afr J AIDS Res. 2013;12(1):1-8.

51. WHO. Monitoring response to ART and the diagnosis of treatment failure Consolidated ARV guidelines. 2013. http://www.who.int/hiv/pub/guide lines/arv2013/art/artmonitoring/en/.

52. van der Loeff MF, Larke N, Kaye S, Berry N, Ariyoshi K, Alabi A, et al. Undetectable plasma viral load predicts normal survival in HIV-2-infected people in a West African village. Retrovirology. 2010;7:46.

53. Peter T, Zeh C, Katz Z, Elbireer A, Alemayehu B, Vojnov L, et al. Scaling up HIV viral load - lessons from the large-scale implementation of HIV early infant diagnosis and CD4 testing. J Int AIDS Soc. 2017;20(7):e25008.

54. Lecher S, Williams J, Fonjungo PN, Kim AA, Ellenberger D, Zhang G, et al. Progress with scale-up of HIV viral load monitoring — seven Sub-Saharan African Countries, January 2015-June 2016. MMWR Morb Mortal Wkly Rep. 2016;65(47):1332-5.

55. Requena S, Trevino A, Cabezas T, Garcia-Delgado R, Amengual MJ, Lozano $A B$, et al. Drug resistance mutations in HIV-2 patients failing raltegravir and influence on dolutegravir response. J Antimicrob Chemother. 2017;72(7):2083-8.

56. Poveda E, Rodes B, Toro C, Soriano V. Are fusion inhibitors active against all HIV variants? AIDS Res Hum Retroviruses. 2004;20(3):347-8.

57. Roquebert B, Damond F, Collin G, Matheron S, Peytavin G, Benard A, et al. HIV-2 integrase gene polymorphism and phenotypic susceptibility of HIV-2 clinical isolates to the integrase inhibitors raltegravir and elvitegravir in vitro. J Antimicrob Chemother. 2008:62(5):914-20.

58. Charpentier C, Larrouy L, Collin G, Damond F, Matheron S, Chene G, et al. In-vitro phenotypic susceptibility of HIV-2 clinical isolates to the integrase inhibitor S/GSK1349572. AIDS. 2010;24(17):2753-5.

59. Smith RA, Raugi DN, Pan C, Sow PS, Seydi M, Mullins Jl, et al. In vitro activity of dolutegravir against wild-type and integrase inhibitor-resistant HIV-2. Retrovirology. 2015;12:10.

60. Trevino A, Cabezas T, Lozano AB, Garcia-Delgado R, Force L, FernandezMontero JM, et al. Dolutegravir for the treatment of HIV-2 infection. J Clin Virol. 2015;64:12-5.

61. Witvrouw M, Pannecouque C, Switzer WM, Folks TM, De Clercq E, Heneine W. Susceptibility of HIV-2, SIV and SHIV to various anti-HIV-1 compounds: implications for treatment and postexposure prophylaxis. Antivir Ther. 2004;9(1):57-65.

62. Desbois D, Roquebert B, Peytavin G, Damond F, Collin G, Benard A, et al. In vitro phenotypic susceptibility of human immunodeficiency virus type 2 clinical isolates to protease inhibitors. Antimicrob Agents Chemother. 2008;52(4):1545-8.

63. WHO. Update of recommendations on first- and second-line antiretroviral regimens 2019. https://apps.who.int/iris/bitstream/handle/10665 325892/WHO-CDS-HIV-19.15-eng.pdf?ua=1.

64. Trevino A, de Mendoza C, Caballero E, Rodriguez C, Parra P, Benito R, et al. Drug resistance mutations in patients infected with HIV-2 living in Spain. J Antimicrob Chemother. 2011;66(7):1484-8.

65. Jallow S, Vincent T, Leligdowicz A, De Silva T, Van Tienen C, Alabi A, et al. Presence of a multidrug-resistance mutation in an HIV-2 variant infecting a treatment-naive individual in Caio Guinea Bissau. Clin Infect Dis. 2009;48(12):1790-3.

66. Jallow S, Alabi A, Sarge-Njie R, Peterson K, Whittle H, Corrah T, et al. Virological response to highly active antiretroviral therapy in patients infected with human immunodeficiency virus type 2 (HIV-2) and in patients dually infected with HIV-1 and HIV-2 in the Gambia and emergence of drug-resistant variants. J Clin Microbiol. 2009:47(7):2200-8.

67. Charpentier C, Eholie S, Anglaret X, Bertine M, Rouzioux C, AvettandFenoel V, et al. Genotypic resistance profiles of HIV-2-treated patients in West Africa. Aids. 2014;28(8):1161-9.

68. Raugi DN, Smith RA, Ba S, Toure M, Traore F, Sall F, et al. Complex patterns of protease inhibitor resistance among antiretroviral treatmentexperienced HIV-2 patients from Senegal: implications for second-line therapy. Antimicrob Agents Chemother. 2013:57(6):2751-60.

69. Duarte F, Miranda AC, Peres S, Diogo I, Goncalves F, Carvalho AP, et al. Transmitted drug resistance in drug-naive HIV-2 infected patients. AIDS. 2016;30(10):1687-8.

70. Charpentier C, Camacho R, Ruelle J, Eberle J, Gurtler L, Pironti A, et al. HIV-2EU-supporting standardized HIV-2 drug-resistance interpretation in Europe: an update. Clin Infect Dis. 2015;61(8):1346-7.

71. May M, Sterne JA, Sabin C, Costagliola D, Justice AC, Thiebaut R, et al. Prognosis of HIV-1-infected patients up to 5 years after initiation of HAART: collaborative analysis of prospective studies. AIDS. 2007;21(9):1185-97.

72. Hernandez-Avila JE, Palacio-Mejia LS, Hernandez-Romieu A, BautistaArredondo S, Sepulveda Amor J, Hernandez-Avila M. Implementation and operational research: effect of universal access to antiretroviral therapy on HIV/AIDS mortality in Mexico 1990-2011. J Acquir Immune Defic Syndr. 2015;69(3):e100-8.

73. Gueler A, Moser A, Calmy A, Gunthard HF, Bernasconi E, Furrer H, et al. Life expectancy in HIV-positive persons in Switzerland: matched comparison with general population. AIDS. 2017;31(3):427-36.

74. Mills EJ, Bakanda C, Birungi J, Chan K, Ford N, Cooper CL, et al. Life expectancy of persons receiving combination antiretroviral therapy in low-income countries: a cohort analysis from Uganda. Ann Intern Med. 2011;155(4):209-16.

75. Johnson LF, Mossong J, Dorrington RE, Schomaker M, Hoffmann CJ, Keiser $\mathrm{O}$, et al. Life expectancies of South African adults starting antiretroviral treatment: collaborative analysis of cohort studies. PLoS Med. 2013;10(4):e1001418.

76. Nsanzimana S, Remera E, Kanters S, Chan K, Forrest JI, Ford N, et al. Life expectancy among HIV-positive patients in Rwanda: a retrospective observational cohort study. Lancet Global Health. 2015;3(3):e169-77. 
77. Asiki G, Reniers G, Newton R, Baisley K, Nakiyingi-Miiro J, Slaymaker E, et al. Adult life expectancy trends in the era of antiretroviral treatment in rural Uganda (1991-2012). AIDS. 2016;30(3):487-93.

78. Lawn SD, Harries AD, Anglaret X, Myer L, Wood R. Early mortality among adults accessing antiretroviral treatment programmes in sub-Saharan Africa. AIDS. 2008;22(15):1897-908.

79. Honge BL, Jespersen S, Aunsborg J, Mendes DV, Medina C, da Silva Te D, et al. High prevalence and excess mortality of late presenters among HIV1, HIV-2 and HIV-1/2 dually infected patients in Guinea-Bissau - a cohort study from West Africa. Pan Afr Med J. 2016;25:40.

80. Jespersen S, Honge BL, Esbjornsson J, Medina C, da Silva Te D, Correira FG, et al. Differential effects of sex in a West African cohort of HIV-1, HIV-2 and HIV-1/2 dually infected patients: men are worse off. Trop Med Int Health. 2016;21(2):253-62.

81. Tchounga B, Ekouevi DK, Balestre E, Dabis F. Mortality and survival patterns of people living with HIV-2. Current Opin HIV AIDS. 2016;11(5):537-44.

82. UNAIDS. 90-90-90 - an ambitious treatment target to help end the AIDS epidemic 2017. www.unaids.org/en/resources/docum ents/2017/90-90-90.

83. Barth RE, van der Loeff MF, Schuurman R, Hoepelman Al, Wensing AM. Virological follow-up of adult patients in antiretroviral treatment programmes in sub-Saharan Africa: a systematic review. Lancet Infect Dis. 2010;10(3):155-66.

84. UNAIDS. Undetectable untransmittable public health and hiv viral load suppression 2018. http://www.unaids.org/sites/default/files/media_asset /undetectable-untransmittable_en.pdf.

85. Honge BL, Jespersen S, Medina C, Te DS, da Silva ZJ, Christiansen M, et al. The challenge of discriminating between HIV-1, HIV-2 and HIV-1/2 dual infections. HIV Med. 2018;19(6):403-10.

86. Lindman J, Honge BL, Kjerulff B, Medina C, da Silva ZJ, Erikstrup C, et al. Performance of Bio-Rad HIV-1/2 Confirmatory Assay in HIV-1, HIV-2 and HIV-1/2 dually reactive patients-comparison with INNO-LIA and immunocomb discriminatory assays. J Virol Methods. 2019;268:42-7.

87. Montgomery ET, Atujuna M, Krogstad E, Hartmann M, Ndwayana S, O'Rourke S, et al. The invisible product: preferences for sustained-release, long-acting pre-exposure prophylaxis to hiv among south african youth. J Acquir Immune Defic Syndr. 2019;80(5):542-50.

\section{Publisher's Note}

Springer Nature remains neutral with regard to jurisdictional claims in published maps and institutional affiliations.
Ready to submit your research? Choose BMC and benefit from:

- fast, convenient online submission

- thorough peer review by experienced researchers in your field

- rapid publication on acceptance

- support for research data, including large and complex data types

- gold Open Access which fosters wider collaboration and increased citations

- maximum visibility for your research: over 100M website views per year

At BMC, research is always in progress.

Learn more biomedcentral.com/submissions 